\title{
SQUAMOUS CELLED CARCINOMA IN A CYSTIC TERATOMA OF THE OVARY WITH INFECTION
}

JANE M. Fullerton, M.B., D.P.H., F.C.Path.

Pathologist, Bermondsey and Southwark Hospitals Group.

DERMOID CYSTS of the ovary account for approximately $7 \%$ of all ovarian abnormalities but malignant change is rare, occurring only from $0.5 \%$ to $5 \%$ of cystic teratomas as reported in the literature by Koucky (1925), Weiner (1915), and Peterson (1957) reviewd 222 cases, but of these 103 were not studied and prior to his review the total of cases in the literature was 65 as collected by Hall, Caband and Sullivan (1955).

In the following case squamous carcinomatous changes occurred in a cystic dermoid of the ovary and of the malignant changes this is recognised to be the commonest i.e., $88 \%$ (Novak, 1958). Other malignant changes seen have included a few cases of sarcoma (Burgess and Shutter, 1954, Peterson, 1957).

\section{Case Report}

In July 1958, Miss A, aged 58, was referred by her doctor to New Cross General Hospital. The patient thought she had "rheumatism of the bowel"; she was losing weight and felt weak and tired. The menarche was at 17 and the menopause at 53 , the menstrual cycles being regular. She had not noticed any recent vaginal bleeding or discharge and micturition was normal. For three weeks she had noticed that her stools were pale but there had not been any alteration in bowel habit. Previously her health had been good, she had not had any operations and had never been pregnant.

On examination, she was a pale, emaciated woman with a hirsute chin and with slight ankle oedema. Temperature normal. The abdomen was enlarged by a swelling arising from the pelvis and extending to the umbilicus. There was no tenderness and the surface of the mass was nodular. No free fluid was detected. The liver was enlarged to one finger breadth below the costal margin. As she was virgo intacta, a rectal examination was made which confirmed the presence of a cystic mass in the pelvis. A diagnosis of ovarian carcinoma was made and she was admitted for laparotomy.

\section{Pre-operative Investigations:}

Hb. $43 \%$ (7g. $/ 100 \mathrm{ml}$.). Film: Severe normochronic anaemia. Five pints of whole blood were cross matched, three being transfused before the operation. She showed a cold agglutination to a titre of 1 in 200 which was in favour of malignancy (Stratton, 1943; Gallico, 1947). Chest X-ray:- Clear lung fields except for a partly calcified shadow in the second right inter-space.

\author{
J. S. Tomkinson, M.B., F.R.C.S., M.R.C.O.G. \\ Gynaecologist, New Cross General Hospital, London \\ S.E.14. \\ Obstetric Surgeon, Guy's Hospital, London, S.E.1.
}

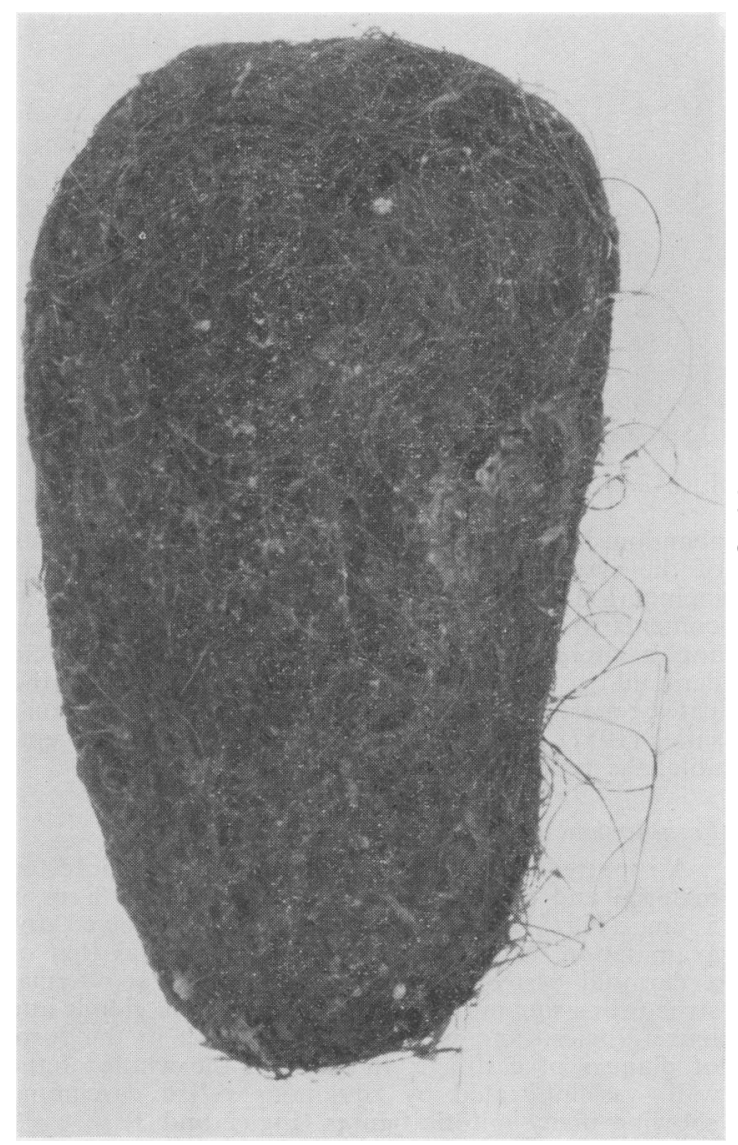

Fig. 1.-Hair ball $10 \times 8 \times 5 \mathrm{~cm}$.

Operation: A week later the abdomen was opened through a left low paramedian incision. Many recent and old adhesions were encountered around a cystic mass which was firmly fixed to the anterior abdominal wall, bladder, colon and rectum and other pelvic organs. Before any dissection was carried out the cyst was seen to be ruptured and leaking offensively smelling sebaceous material containing hairs. It was not possible to identify the ovaries, Fallopian tubes or uterus; these were obliterated and were presumably embedded in the pelvis and hidden by the firmly adherent lower pole of the tumour. An attempt to dissect the cyst wall was 


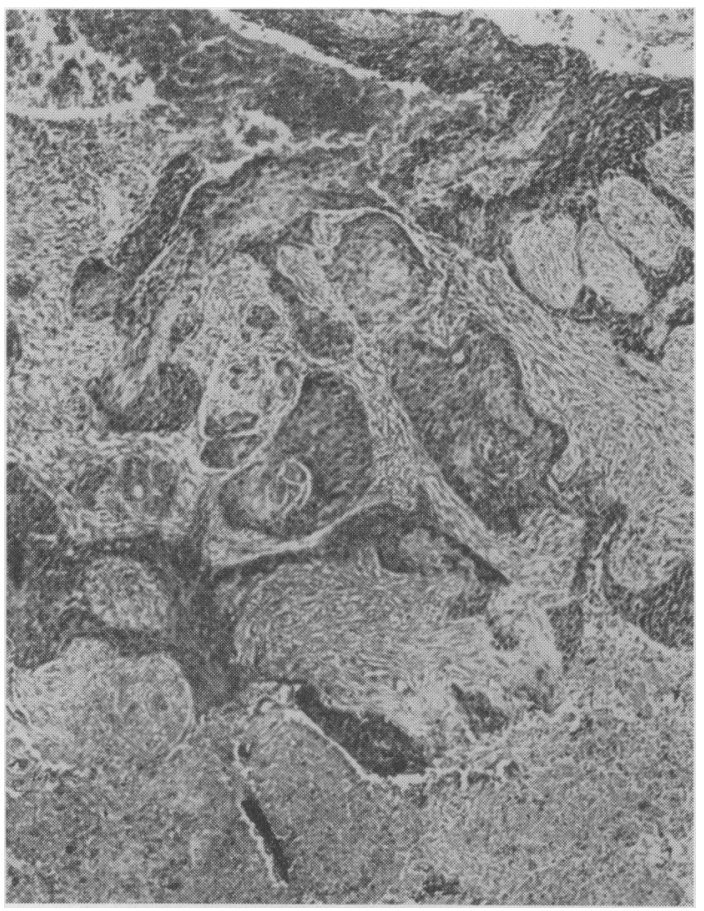

FIG. 2.-Section of cyst wall. x25.

abandoned and only the superior and posterior walls of the cyst were removed together with its contents including a hair ball. Swabs were taken of the cyst contents for culture, which grew E. coli, Ps. pyocanea and a diphtheroid. Infection in a malignant cystic dermoid is claimed to occur in only $0.4 \%$ of the cases reported by Blackwell (1946) and in Peterson's series (1957) only one case with infection was acceptable, the type of organism not being recorded.

\section{Pathological Report of Tumour}

A ruptured cystic tumour containing grossly infected material and a hair ball measuring $10 \mathrm{~cm}$. $\times 8 \mathrm{~cm}$. $x$ $5 \mathrm{~cm}$. (Fig. 1) filling the cavity was received for examination. Microscopically the picture was that of a dermoid cyst showing the presence of ectodermal structures-squamous epithelial, sebaceous glands and hair follicles-and mesodermal elements in the form of plaques of cartilage. In addition the whole of the wall was infiltrated by squamous celled carcinoma showing many mitotic figures (Fig. 2 and 3).

Progress: Two pints of whole blood were transfused during and immediately after the operation. Penicillin 500,000 units twice daily was injected for seven days and cystamycin one vial twice daily for eighteen days

She was free of pain until she died on the 51st post-operative day. A faecal fistula developed through the abdominal wound on the 28th day.

Unfortunately a post-mortem examination was not carried out.

\section{Summary}

A case of a cystic teratoma of ovary with squamous carcinomatous changes is reported

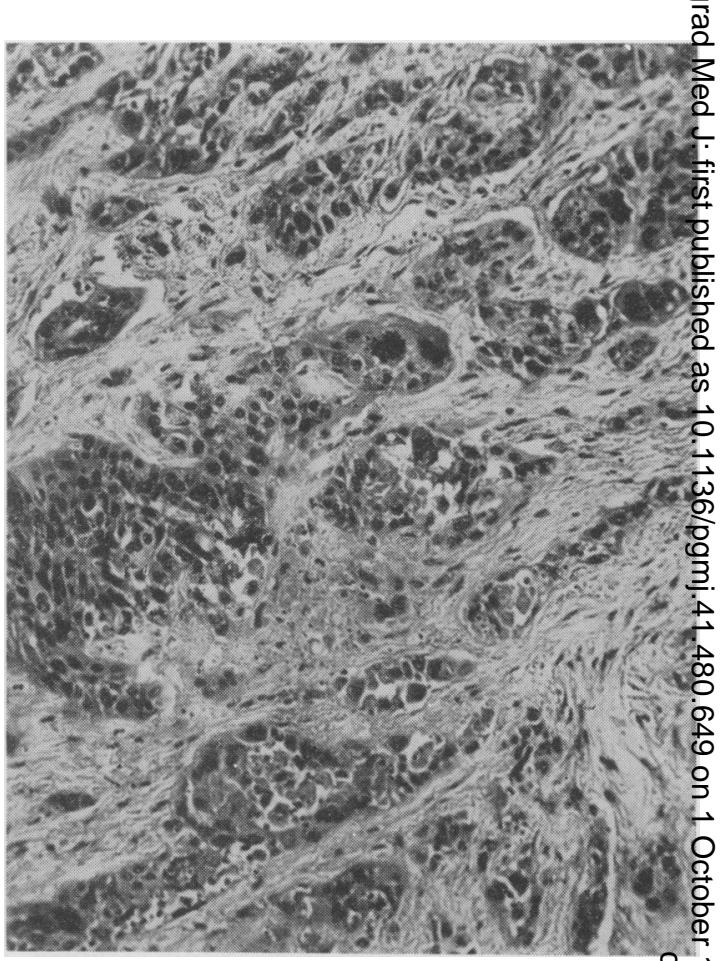

FIG. 3.-Section showing mitosis. $x 127$.

which showed the added features of interestin the presence of a circulatory cold antibody? the patient's blood and infection of the cyst cavity

\section{REFERENCES}

Blackwell, W. J. (1946): Dermoid Cysts of Ovar Their Clinical and Pathologic Significance, Ame $\bar{E}$ J. Obstet. Gynec., 51, 151 .

Burgess, G. F., and SHUTter, H. W. (1954) Malignancy Originating in Ovarian Dermoid廌 Obstet. and Gynec., 4, 567.

Hall, J. E., Cabaud, P. G., and Sullivan, T. (1955)응 Squamous Carcinoma Arising in Previously Benig Cystic Teratoma, Obstet. and Gynec., 6, 93. 웅

Gallico, E. (1947): Le Agglutinine e Figore ne Siero dei ancerosi, Tumori., 21, 189.

KouCKY, J. D. (1925): Ovarian Dermoids : a Stud of One Hundred Consecutive Cases, Ann. Surg., $81,821$.

MASSON, J. C., and OChSENHIRT, N. C. (1929)? Squamous Cell Carcinoma Arising in a Dermoid Cyst of the Ovary: Report of Three Cases, Surg: Gynec. Obstet. 48, 702.

Novak, E. (1958): Textbook of Gynaecologic and Obstetric Pathology. 3rd Edition. PhiladelphiaN Saunders.

PeTERSON, W. F. (1957): Malignant Degeneration of Benign Cystic Teratomas of the Ovary: a Collective Review of the Literature, Obstet. Gynec. Surv., 12 793.

Stratton, F. (1943): Some Observations on Auto haemagglutination, Lancet, i, 613.

WIENER, S. (1915): A Study of the Complications of Ovarian Tumors, Amer. J. Obstet. Dis. Wom., 72 \% 209. 